\title{
WATER AND NUTRIENTS REUSE WITHIN CLOSED SOILLESS CULTURE SYSTEMS
}

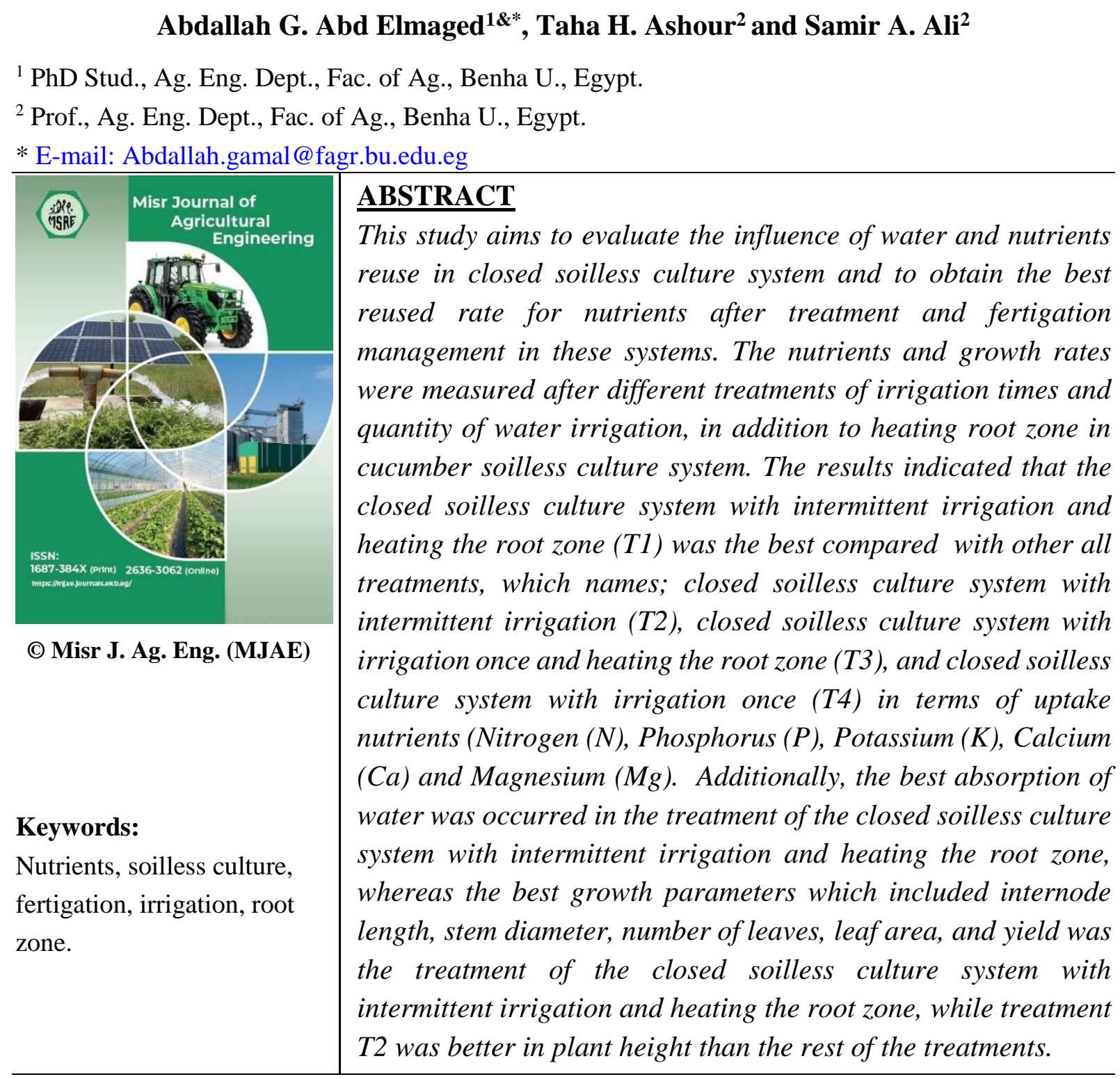

\section{INTRODUCTION}

$\mathrm{D}$ ue to limited availability of water and rising awareness on environmental issues, evaluation and comparison of different soilless growing systems in terms of yield, evapotranspiration, irrigation scheduling, water use efficiency and environmental issues such as discharged nutrient solution volumes may be crucial for decision-making processes of growers in developing countries where greenhouse soilless production systems are rapidly expanding. From the points of environmentalism, sustainability, water availability and management, the closed systems and relatively infrequent irrigations are found applicable with an acceptable risk of yield decrease (Merica $\boldsymbol{e t}$ al., 2011). The scarcity of good quality water in the irrigated areas of the Mediterranean Basin forces growers to use saline water. Under those conditions, drip irrigation with open cycle management and high leaching rate (20-40\%) is the most common practice for soilless production of vegetables (Incrocci et al., 2006). The need 
of large amounts and high quality vegetable products to meet the growing demand of world population justifies the development of technologies which synchronize the nutrient solution demand and supply to greenhouse plants in order to achieve crop yield optimization. The knowledge about water and nutrient uptake by plants is crucial for developing control strategies which make possible to supply the required amounts of water and nutrients for maximum crop growth and development (Kläring, 2001). Being a scarce resource, unevenly distributed and often in low quality, water is the key element of agriculture in arid and semiarid regions of the Mediterranean. Besides, due to excessive use of water together with high losses, improper management and harmful effects of fertilizers and pesticides on the environment, it is necessary to use water in plant scale effectively and sustainably (Hamdy, 2006). Problems caused by water and land resources and policies to protect the environment oriented the growers to agricultural practices likely to give the highest yield from per unit of water and land. Protected cultivation is of great priority among the practices concerned. In agriculture, soilless cropping represents the most suitable cultivation technique apt to achieve a theoretical $100 \%$ efficiency of water and nutrient use. This is possible through a high control of input streams in the cultivation system. Soilless cultivation indeed allows high precision in nutrient and water management so that particular agronomic techniques, which are risky in other cultivation systems (e.g., nutrient depletion or the maintenance of low nutrient concentrations in the root zone), can be managed more safely under soilless conditions. Even in the so-called open (freedrain) cycles, water and nutrient losses can be minimized by the combination of sensing technologies and nutrient delivery strategies aiming at zero emissions. However, soilless cropping allows collection and reuse of the drainage in closed growing systems, thereby avoiding or minimizing water and nutrient losses into the environment (Massa et al., 2020). Some of the driving force for the development of a closed fertigation system includes restricting environmental laws and regulations aiming to reduce nutrient leaching to the environment; significant savings of water and nutrients; better control of nutrient supply; and reduced risk of ground water contamination (Magen, 1999). In the Netherlands, law prohibits growers to let the excess nutrients solution run off because of surface and ground water pollution with nutrients and pesticides (Runia and Amsing, 2001). As yield, and nutrients and water savings showed positive effects, the application of a closed fertigation system was asserted. The established simple nutrient recycling system can be considered as a practical alternative to the conventional cropping practice using open fertigation (Dhakal et al., 2005). Closed cycle soilless system involves growing greenhouse plants by collecting left over nutrient solution (NS), blending it with fresh NS, and recirculating in subsequent irrigations. Closed cycle soilless systems arouse lively interest because they increase water- and fertilizer-use efficiency and reduce environmental pollution caused by fertilizer runoff (Rouphael et al., 2004). However, large scale adoption of closed cycle systems is limited, particularly in production areas where the greenhouse industry is characterized by a low-technology profile, mainly due to the difficulty in managing recirculating NS (Ikeda et al., 2002).

\section{MATERIALS AND METHODS}

\subsection{Materials:}

\subsubsection{Greenhouses:}

The experiment was carried out at the Agricultural Research and Experiment Center of Faculty of Agriculture, Benha University ( $30^{\circ} 21^{`} \mathrm{~N}$ and $\left.31^{\circ} 13^{`} \mathrm{E}\right)$. A multi-Spanish greenhouse used 
for experiment with dimensions 24 m width and $40 \mathrm{~m}$ length; walls were covered with $200 \mu \mathrm{m}$ polyethylene and the aspects were covered with fiberglass. The greenhouse was cooled with evaporative cooling system (pad and fan system). The root zone was heated by hot water plastic pipes system. The planting was carried out in agricultural root zone media putted on plastic media with dimensions $25 \mathrm{~cm}$ width, $30 \mathrm{~cm}$ height and $6 \mathrm{~m}$ length and was installed on the ground with approximately tilt angle of $20^{\circ}$ to collect the drainage water in plastic hole. The planting media consisted from 50:25:25 of bitmous, perlite and vermiculite, respectively. The cucumber (Cucumis sativus L) plant was selected in this experiment.

\subsection{Methods:}

\subsubsection{Design of Experiment:}

The treatments were arranged in a randomized complete design in three replicates. Four treatments were used and named as follow; T1 is the closed soilless culture systems with intermittent irrigation and heating the root zone, $\mathbf{T} 2$ is the closed soilless culture systems with intermittent irrigation, T3 is the closed soilless culture systems with one time irrigation and heating the root zone, and T4 is the closed soilless culture systems with one time irrigation. The cultivated area for each treatment was $1.5 \mathrm{~m}^{2}$ (6.0 m long $\times 0.25 \mathrm{~m}$ width) and the volume of the soil mixture was $450 \mathrm{~L}$ for each replicate. In this experiment, drip irrigation system was used and water consumptive use ( $\mathrm{mm} /$ day) was calculated according to the Penman-Monteith method (FAO, 1991) using the collected local weather data from weather station that located in Moshtohor, Egypt. For fertilization, the fertilizer requirements of cucumber were applied according to recommendations of Agronomy Research Institute (ARC), Ministry of Agriculture and Land Reclamation, Egypt. The irrigation and fertilization systems were the same for all treatments.

\subsubsection{Experiment measurements:}

The samples (agricultural media, irrigation and drainage water, plant) were taken for tests. The agricultural media samples were collected before planting for mechanical and chemical analysis. The water samples were taken before and after each irrigation time. The plant samples were collected after 12 day from planting and then every weak. For Total nutrients tests, the total nitrogen (TN) content was measured by using semi-micro Kjeldahl method. The total phosphorus (TP) content was measured by using a spectrophotometer and Potassium $(\mathrm{K})$, calcium $(\mathrm{Ca})$ and magnesium $(\mathrm{Mg})$ contents were determined using flamphotometer.

Table (1): The concentration of total nutrients in the solution.

\begin{tabular}{|c|c|c|c|c|c|c|c|}
\hline \multirow{2}{*}{ Date } & \multicolumn{6}{|c|}{ Total nutrients (ppm) } & \multirow{2}{*}{$\mathrm{PH}$} \\
\hline & $\mathrm{N}$ & $\mathrm{P}$ & $\mathrm{K}$ & $\mathrm{Ca}$ & $\mathrm{Mg}$ & $\mathrm{EC}$ & \\
\hline $14 / 10 / 2019$ & 33 & 37 & 18 & 44 & 11 & 1120 & 6.4 \\
\hline $16 / 10 / 2019$ & 60 & 60 & 60 & 100 & 15 & 1850 & 6.15 \\
\hline $02 / 11 / 2019$ & 70 & 60 & 80 & 120 & 15 & 1932 & 6.05 \\
\hline $15 / 11 / 2019$ & 70 & 70 & 100 & 120 & 15 & 2014 & 5.96 \\
\hline $10 / 12 / 2019$ & 70 & 70 & 120 & 130 & 20 & 2246 & 5.83 \\
\hline $20 / 12 / 2019$ & 80 & 80 & 140 & 150 & 20 & 2315 & 5.78 \\
\hline $01 / 01 / 2020$ & 80 & 90 & 160 & 150 & 25 & 2426 & 5.64 \\
\hline $06 / 01 / 2020$ & 70 & 70 & 120 & 130 & 20 & 2218 & 5.85 \\
\hline
\end{tabular}


Date 14/10/2019 It is the concentration of elements before planting in the soil, it should be to mention that the cultivated soil is fertile, consisting of betmos, perlite and vermiculite, and concentration of elements at the end of the planting season is the last value of the elements in the Drainage as shown in the diagram for each element

\subsubsection{Plant growth parameters:}

Three plants were randomly selected from each treatment for measuring growth parameters, which include plant height, internode length, stem diameter, leaf area, and yield. The plant height from cotyledons level to the terminal bud, the fifth internode length from the top of the plant after the branches, and the fifth internode diameter from the top of the plant after the branches were measured weekly. Additionally, the number of leaves and the fifth single leaf area from the top of the plant were counted and measured weekly by using digital planimeter, respectively. Finally, the total fruit weight per plant were determined for each harvest and the total yield of one plant for each replicate also was estimated.

\subsection{Statistical analysis:}

The statistical analysis for the obtained data was examined using SPSS software (IBM SPSS Statistics 21, American) and the treatments were compared at 0.05 level probability of significances.

\section{RESULTS AND DISCUSSION}

\section{1. Water Irrigation and Drainage:}

Figure (1) show the Water Irrigation and Drainage of cucumber plant in different treatments (T1 to T4) during the growth period plant. The results indicate that the Drainage of cucumber plant during the growth period which grown in different treatments It differs from one treatment to another because the quantities of irrigation water are added to the cucumber plant based on the Benman Montes equation, which depends on climate data and the crop yield of the cucumber plant. It could be seen that average the Drainage of cucumber plant 23.94, 35.57, 27.81 and 37.70 Lit all plant $^{-1}$ for $\mathrm{T} 1$ to $\mathrm{T} 4$, respectively, after 14 weeks of transplanting. The quantities of irrigation water added to the cucumber plant The least amount of average Drainage per treatment $\mathrm{T} 1$ (23.94) Lit all plant ${ }^{\mathbf{1}}$, due to the availability of ideal conditions for plant growth, roots and absorption of elements due to the warming of the soil around the root zone and the addition of water requirements to the plant in batches, While the highest amount of average Drainage in the treatment T4 (37.70) Lit all plant ${ }^{-1}$.

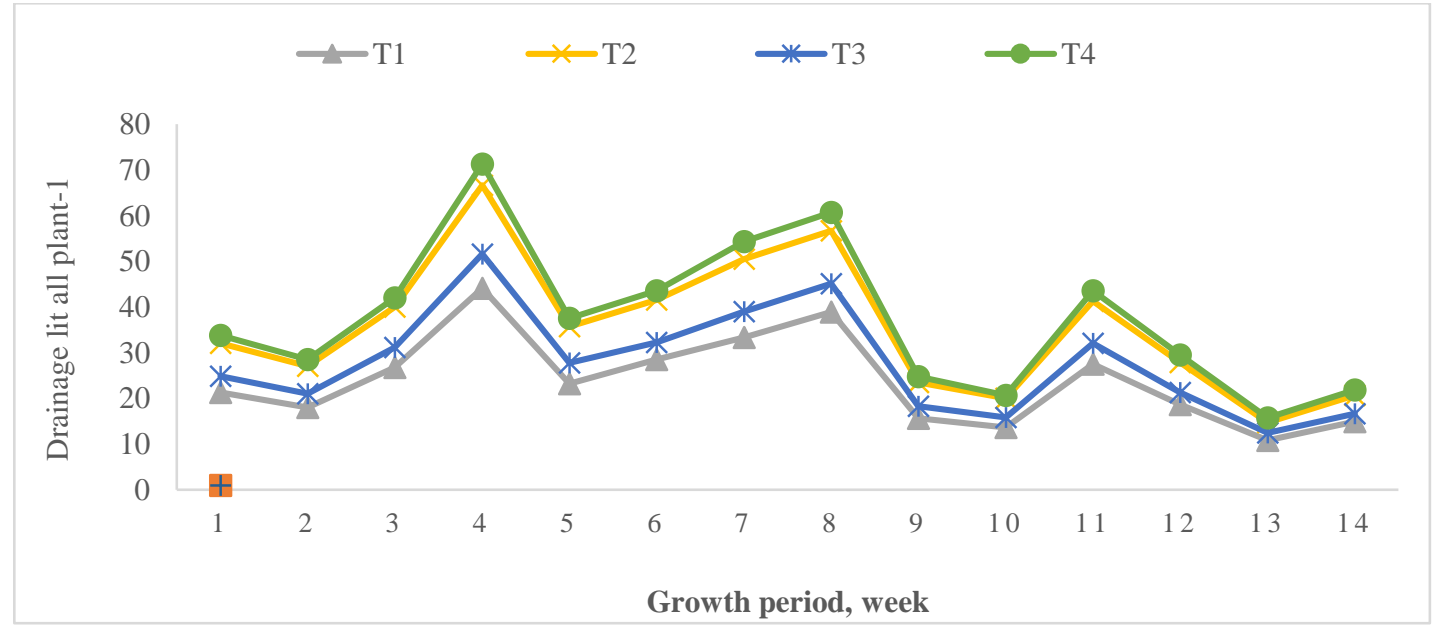

Figure (1): Drainage for cucumber plant during the growth period plant. 
The statistical analysis showed that there was a significant difference between the average Drainage of cucumber for all treatments. The results also indicate that the average plant height was $23.94,35.57,27.81$ and 37.70 Lit all plant $^{-1}$ for $\mathrm{T} 1$ to $\mathrm{T} 4$, respectively. The highest value of Drainage (37.70) Lit all plant ${ }^{-1}$ was found with a treatment of $\mathrm{T} 4$, while the lowest value of Drainage (23.94) Lit all plant ${ }^{-1}$ was found with a treatment of T1.

\section{2. Nutrients concentration:}

\section{2.1. Total nitrogen concentration:}

Figure (2) show the total nitrogen $(\mathrm{N})$ concentration by cucumber plants during the growth period. It should be to mention that the cultivated soil is fertile, consisting of betmos, perlite and vermiculite. The nitrogen content in the nutrient solution added to the plant at time intervals with a different ratio of the absorption element length of plant life. The results indicated that the average nitrogen concentration in the drainage solution was the lowest in treatment T1 (8.13 ppm) compared to other all treatments; T2, T3 and T4, which the nitrogen concentrations were $14.63,10.88$, and $20.63 \mathrm{ppm}$, respectively. This occurs because of higher the absorption of the element due to the availability of environmental conditions appropriate for the roots of the plant appropriate to absorb the elements.

The statistical analysis showed that there was a significant difference between the average total Nitrogen concentrations of cucumber for all treatments. The results also indicated that the average nitrogen concentrations in drainage solution were 8.1, 14.6, 10.88 and $20.63 \mathrm{ppm}$ for T1, T2, T3, and T4, respectively. The highest value of Nitrogen consumption rate was found with a treatment of $\mathrm{T} 1$, while the lowest value of nitrogen consumption rate was found with a treatment of $\mathrm{T} 4$.

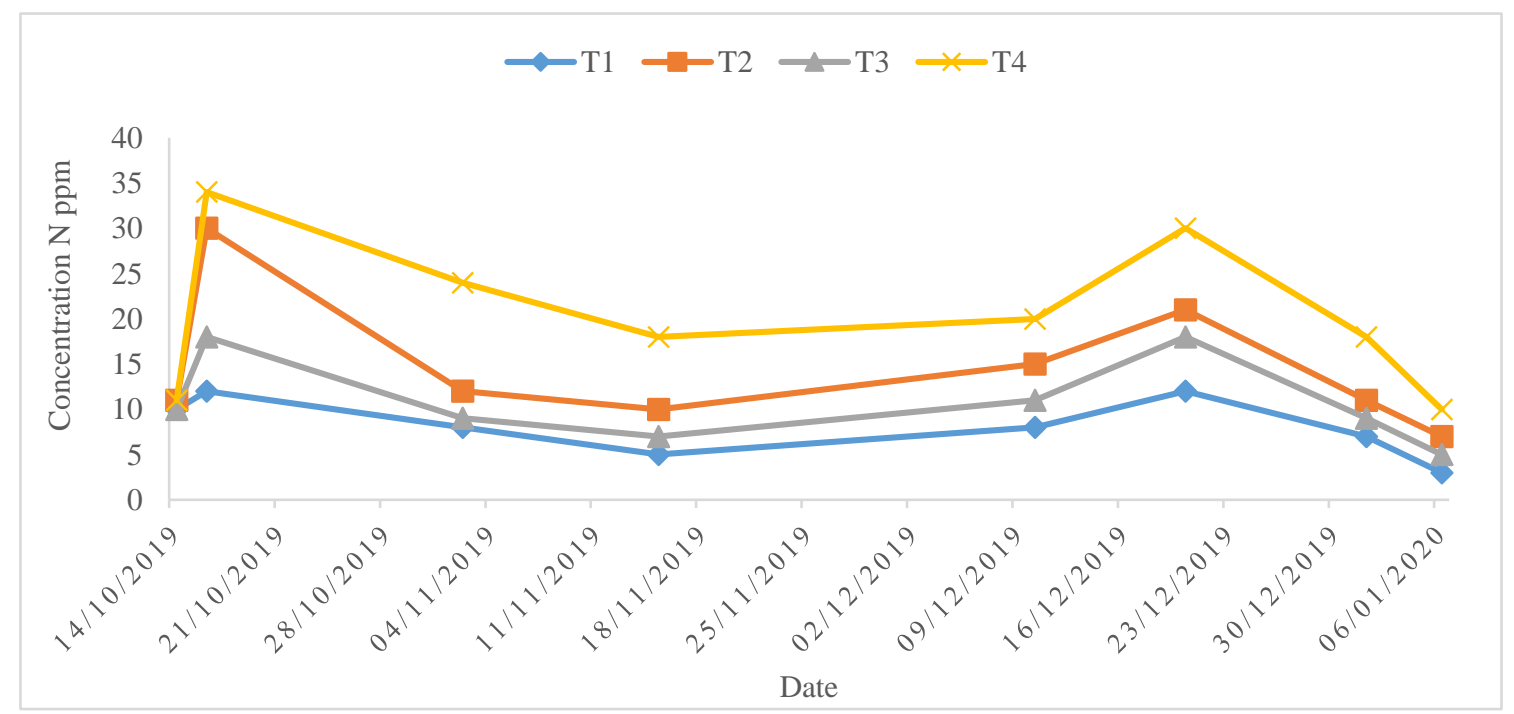

Figure (2): Nitrogen concentration for cucumber plant during the growth period plant.

\section{2. 2. Total Phosphorus concentration:}

Figure (3) show the total phosphorus $(\mathrm{P})$ concentration by cucumber plants during the growth period. The Phosphorus content in the nutrient solution added to the plant at time intervals with a different ratio of the absorption element Length of plant life. The results indicated that the average phosphorus concentration in the drainage solution was the lowest in treatment T1 (10.75 ppm) compared to other all treatments; T2, T3 and T4, which the phosphorus concentrations were $15.5,12.75$, and $23.625 \mathrm{ppm}$, respectively. 


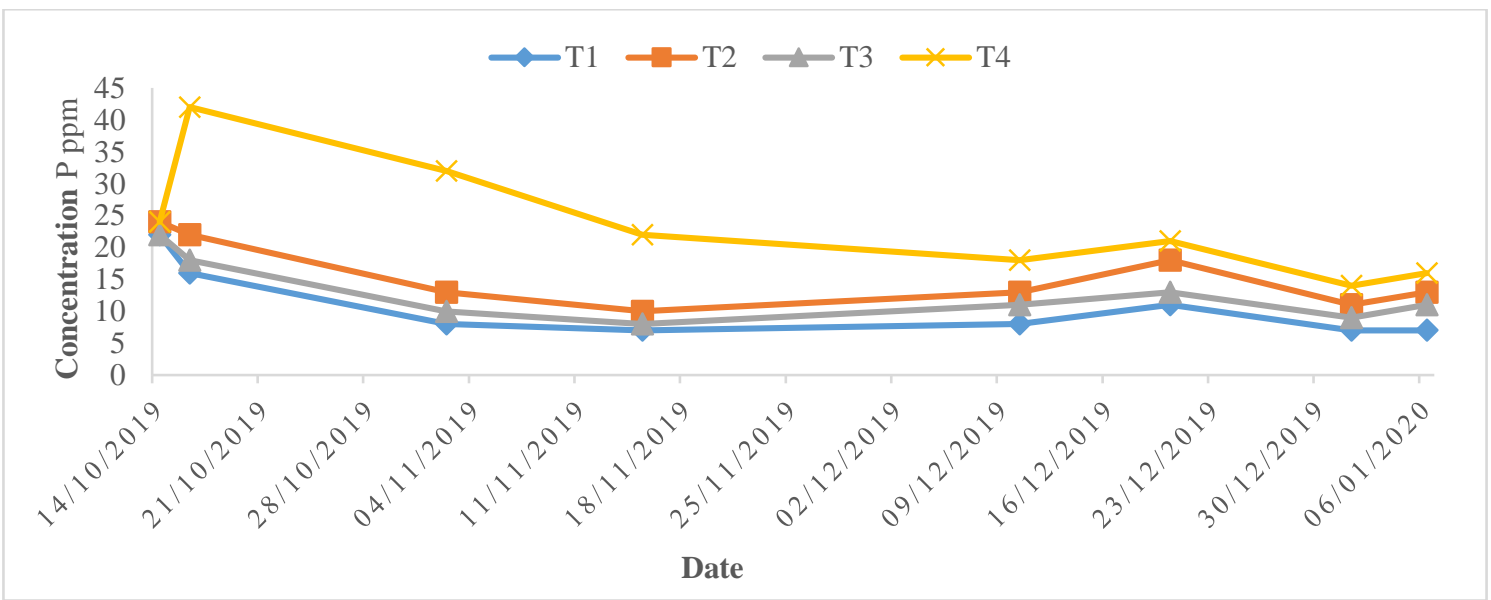

Figure (3): Phosphorus concentration for cucumber plant during the growth period plant.

The statistical analysis showed that there was a significant difference between the average Phosphorus concentrations of cucumber for all treatments. The results also indicate that the average total phosphorus concentration in drainage solution were 10.75, 15.5, 12.75 and 23.625 ppm for T1, T2, T3, and T4, respectively. The highest value of Phosphorus consumption rate was found with a treatment of $\mathrm{T} 1$, while the lowest value of Phosphorus concentration was found with a treatment of T4.

\section{3. 3. Potassium concentration:}

Figure (4) shows the potassium (K) concentration by cucumber plants during the growth period. The Potassium content in the nutrient solution added to the plant at time intervals with a different ratio of the absorption element Length of plant life. The results indicated that the average potassium concentration in the drainage solution was the lowest in treatment $\mathrm{T} 1$ (16.875 ppm) compared to other all treatments; T2, T3 and T4, which the potassium concentrations were $23.5,19.5$, and 28.875 ppm, respectively.

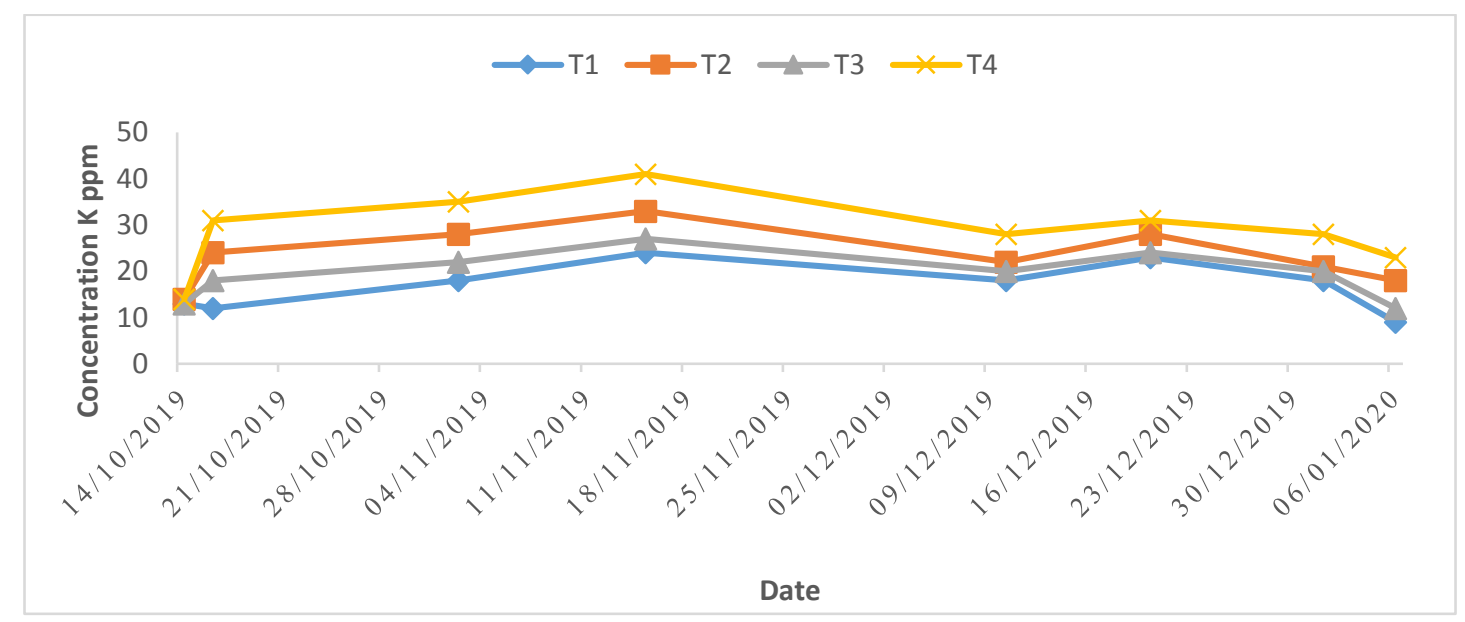

Figure (4): Potassium concentration for cucumber plant during the growth period plant.

The statistical analysis showed that there was a significant difference between the average Potassium concentrations of cucumber for all treatments. The results also indicate that the average Potassium concentration in drainage solution were 16.87, 23.5, 19.5, and $28.87 \mathrm{ppm}$ for T1, T2, T3, and T4, respectively. The highest value of potassium consumption rate was found with a treatment of T1, while the lowest value of Potassium consumption rate was found with a treatment of $\mathrm{T} 4$. 


\section{2. 4. Calcium concentration:}

Figure (5) shows the Calcium (Ca) concentration by cucumber plants during the growth period. The Calcium content in the nutrient solution added to the plant at time intervals with a different ratio of the absorption element Length of plant life. The results indicated that the average calcium concentration in the drainage solution was the lowest in treatment T1 (20.25 ppm) compared to other all treatments; T2, T3 and T4, which the calcium concentrations were 25.37, 23.00 and $30.25 \mathrm{ppm}$, respectively.

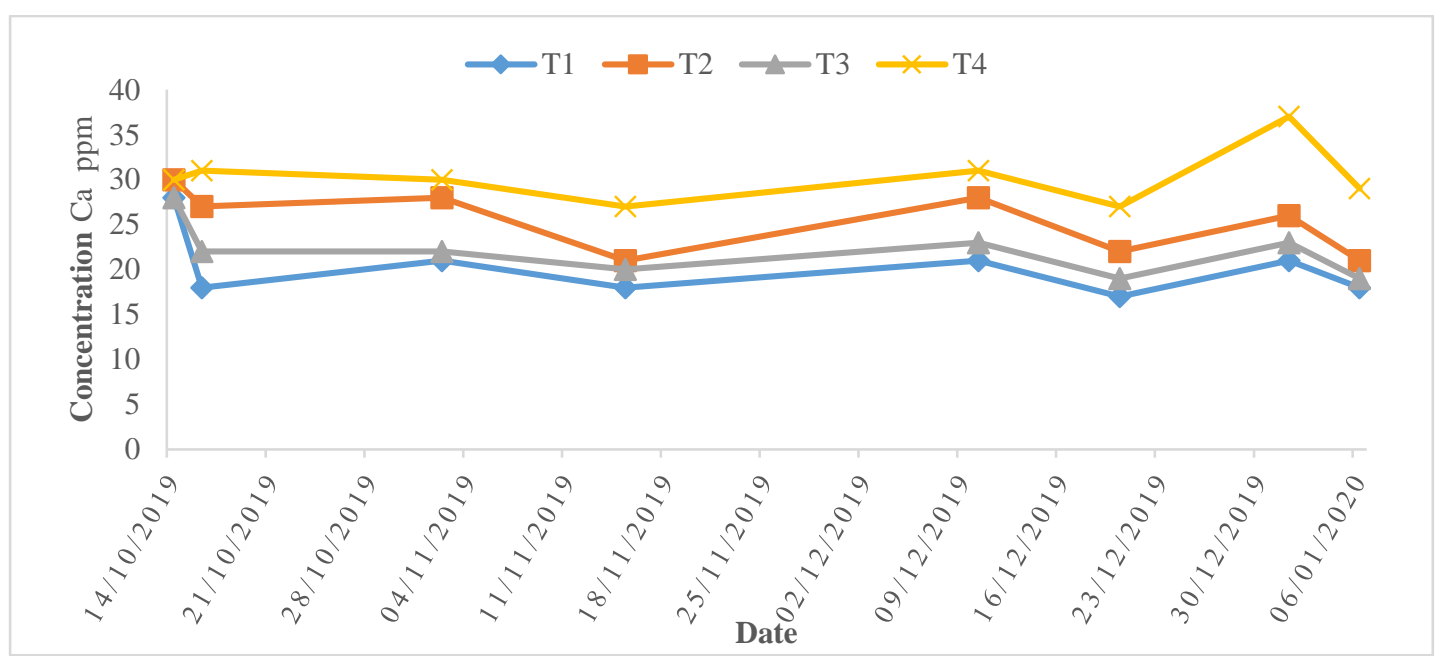

Figure (5): Calcium concentration for cucumber plant during the growth period plant.

The statistical analysis showed that there was a significant difference between the average Calcium concentrations of cucumber for all treatments. The results also indicate that the average Calcium concentrations in drainage solution were 20.25, 25.375, 23.00, and 30.25ppm for T1, $\mathrm{T} 2$, T3, and T4, respectively. The highest value of Calcium consumption rate was found with a treatment of $\mathrm{T} 1$, while the lowest value of Calcium concentrations was found with a treatment of T4.

\section{2. 5. Magnesium concentration:}

Figure (6) show the magnesium ( $\mathrm{Mg}$ ) concentration by cucumber plants during the growth period. The Magnesium content in the nutrient solution added to the plant at time intervals with a different ratio of the absorption element Length of plant life. The results indicated that the average magnesium concentration in the drainage solution was the lowest in treatment $\mathrm{T} 1$ (3.875 ppm) compared to other all treatments; T2, T3 and T4, which the magnesium concentrations were $7.875,5.25$, and 10.125 ppm, respectively.

The statistical analysis showed that there was a significant difference between the average Magnesium concentrations of cucumber for all treatments. The results also indicate that the average Magnesium concentrations in drainage solution were 3.875, 7.875, 5.25, and 10.125 ppm for T1, T2, T3, and T4, respectively. The highest value of Magnesium consumption rate was found with a treatment of T1, while the lowest value of Magnesium consumption rate was found with a treatment of $\mathrm{T} 4$.

\section{3. The plant Parameters:}

Data for cucumber parameters were collected from different treatments during the growth period. These parameters are: vegetative, fresh yield and fresh yield components. 


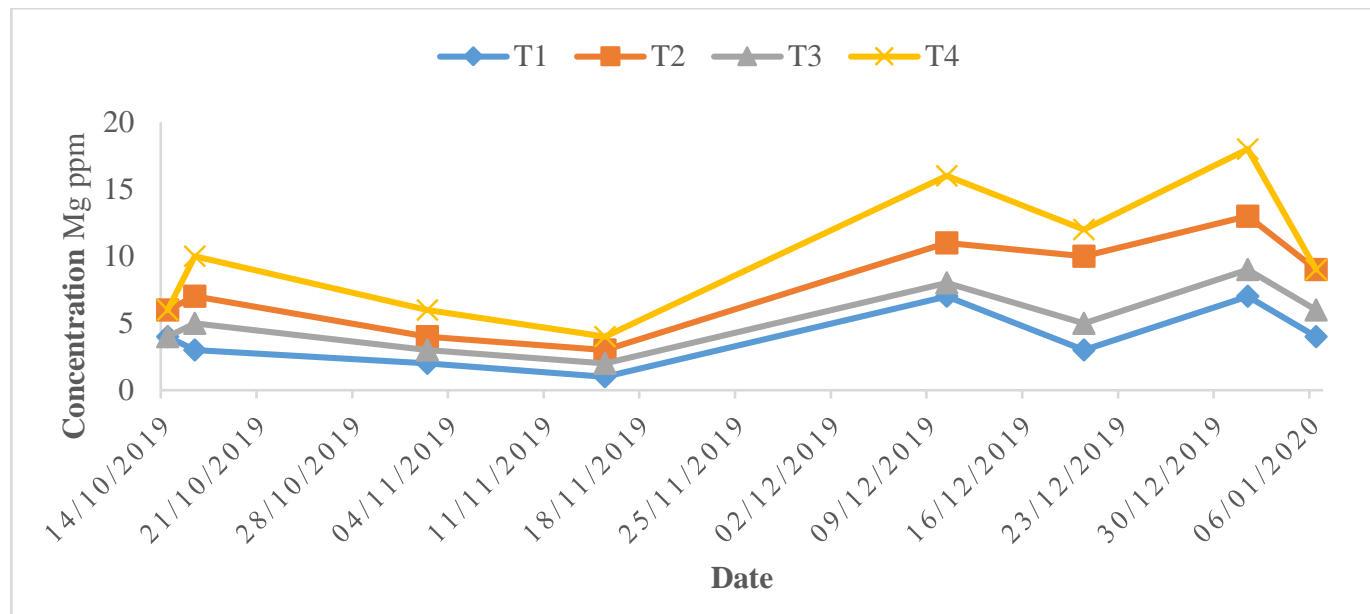

Figure (6): Magnesium concentration for cucumber plant during the growth period plant.

\subsubsection{Vegetative parameters:}

Plant height, number of leaves, stem diameter, Number of internode, Number of branches, Number of flowers, Number of fruits, and leaf area were taken as the most important indicators of vegetative parameter of cucumber grown under different treatments (T1 to T4).

\section{3. 1. 1. Plant height:}

Figure (7) shows the plant height of cucumber plant in different treatments (T1 to T4) during the growth period plant. The results indicate that the height plant of cucumber during the growth period which grown in different treatments increases linearly with the time. It could be seen that the plant height increased from 48.33 to $258.67,49.67$ to $291.00,48.33$ to 271.00 and 45.00 to 251.67 for $\mathrm{T} 1$ to $\mathrm{T} 4$, respectively, after 12 weeks of transplanting.

The statistical analysis showed that there was a significant difference between the average plant heights of cucumber for all treatments. The results also indicate that the average plant height was $194.28,214.83,201.89$ and $185.56 \mathrm{~cm}$ for $\mathrm{T} 1$ to $\mathrm{T} 4$, respectively. The highest value of plant height $(291.00 \mathrm{~cm})$ was found with a treatment of $\mathrm{T} 2$, while the lowest value of plant height $(251.67 \mathrm{~cm})$ was found with a treatment of T4.

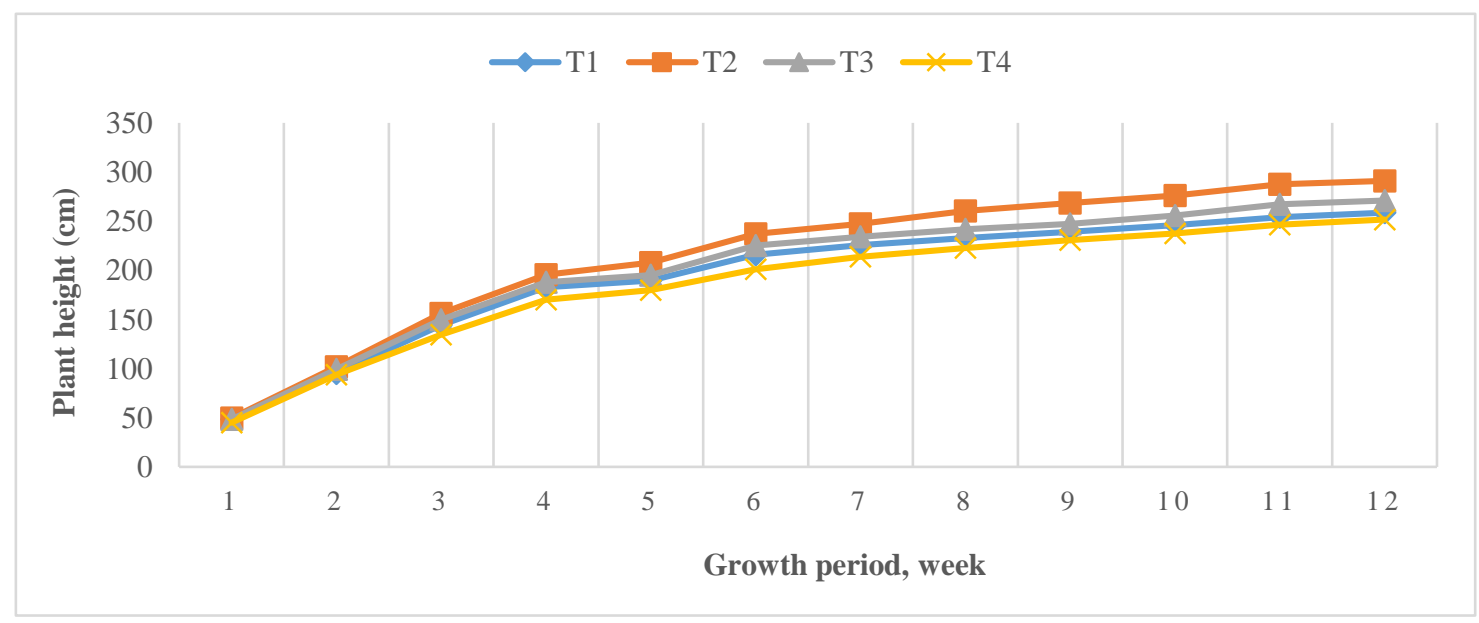

Figure (7): Plant height for cucumber plant during the growth period plant.

Increasing height of cucumber plant for treatments $\mathrm{T} 2$ may be due to intermittent irrigation for these treatments more than treatment T4. The most important part is not the height of plant, the most important is the number of internode on the plant and the length of the internode. The 
more the distance between the internode increases, the more the number of fruits on the plant and not the higher the plant increases, the more this is evident between transactions from $\mathrm{T} 1$, $\mathrm{T} 2$, T3, and T4.

\section{3. 1. 2. Number of leaves:}

Figure (8) shows the number of leaves of cucumber plant under different treatments (T1 to T4) during the growth period of the plant. The results indicate that the number of leaves of cucumber during the growth period increases linearly with the time. It could be seen that the number of leaves increased from 7.00 to $37.33,6.67$ to $33.00,7.00$ to 34.33 and 6.33 to 31.00 for T1 to T4, respectively, after 12 weeks of transplanting.

The statistical analysis showed that there was a significant difference between the average number of leaves of cucumber for all treatments. The results also indicate that the average number of leaves was $26.78,23.17,24.17$ and 21.50 for $\mathrm{T} 1$ to $\mathrm{T} 4$, respectively. The highest value of number of leaves (26.78) was found with a treatment of T1, while the lowest value of number of leaves (21.50) was found with a treatment of T4. Increasing number of leaves of cucumber plant for treatments $\mathrm{T} 1$ and $\mathrm{T} 3$ as expected was due to increasing soil temperatures and soil heating for these treatments more than treatment $\mathrm{T} 4$, by $19.71 \%$ and $11.05 \%$, respectively, and $\mathrm{T} 1$ the best and most leaves are due to intermittent irrigation and soil heating.

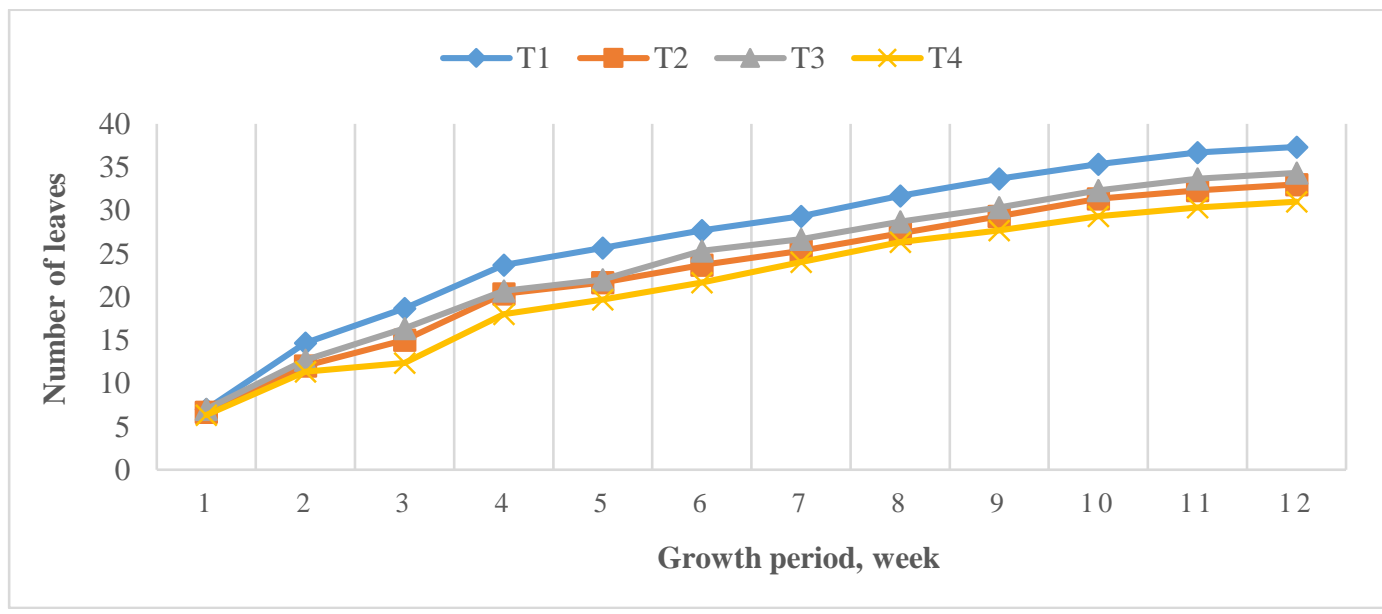

Figure (8): Number of leaves for cucumber plant during the growth period plant.

\section{4. 1. 3. Stem diameter:}

Figure (9) shows the stem diameter of cuccmber plant under different treatments (T1 to T4) during the growth period of the growth period plant. The results indicate that the stem diameter of cucumber increases linearly with the time and decreases linearly with the age of the plant. It could be seen that the stem diameter increased from 6.45 to $7.38,6.22$ to $6.98,6.35$ to 7.07 and 5.96 to $6.73 \mathrm{~mm}$ for T1 to T4, respectively, and decreased from 7.38 to $6.66,6.98$ to $6.44,7.07$ to 6.53 and 6.73 to $6.04 \mathrm{~mm}$ for $\mathrm{T} 1$ to $\mathrm{T} 4$, respectively when the time after transplanting increased from 1 to 12 weeks.

The statistical analysis showed that difference between the average stem diameters of cucumber for all treatments was significant. The results indicate that the average stem diameter was 6.82 , 6.51, 6.63 and $6.15 \mathrm{~mm}$ for $\mathrm{T} 1$ to $\mathrm{T} 4$, respectively. The highest value of stem diameter (7.38 $\mathrm{mm}$ ) was found with a treatment $\mathrm{T} 1$, while the lowest value of stem diameter $(5.43 \mathrm{~mm})$ was found with a treatment (T4) and T1 the best and most stem diameters are due to intermittent irrigation and soil heating. 


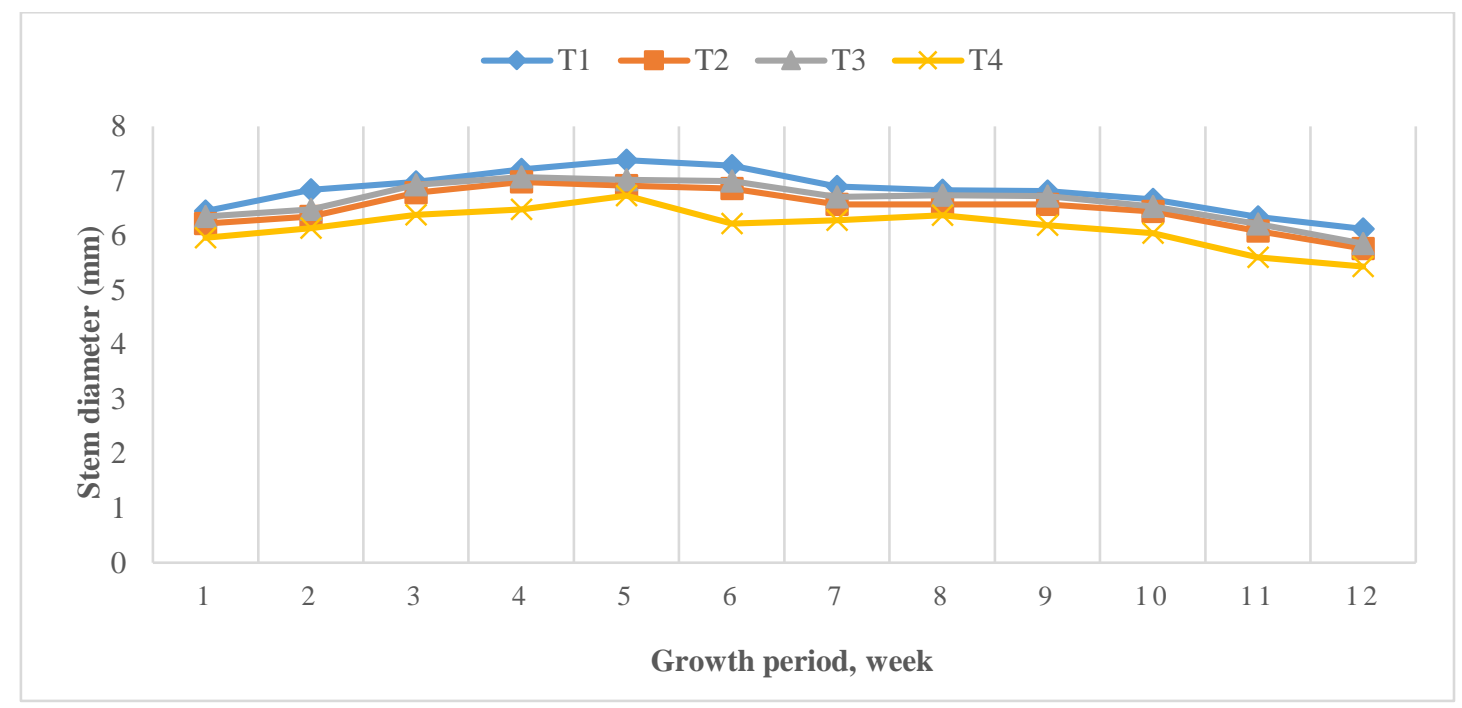

Figure (9): Stem diameter for cucumber plant during the growth period plant.

\section{3. 1. 4. Number of internode:}

Figure (10) shows the number of internode of cucumber plant under different treatments (T1 to T4) during the growth period of plant. The results indicate that the number of internode of cucumber during the growth period which grown in different treatments increases linearly with the time. It could be seen that the number of internode increased from 8.00 to 38.33, 7.67 to $34.00,8.00$ to 35.33 and 7.33 to 32.00 for $\mathrm{T} 1$ to $\mathrm{T} 4$, respectively, when the time after transplanting increased from 1 to 12 weeks.

The statistical analysis showed that difference between the average number of internode of cucumber for all treatments was significant. The results indicate that the average number of internode was $27.78,24.17,25.17$ and 22.50 for $\mathrm{T} 1$ to $\mathrm{T} 4$, respectively. The highest value of number of internode (38.33) was achieved with a treatment T1, while the lowest value of number of internode (32.00) occurred with a treatment (T4), and T1 the best and most number of internode are due to intermittent irrigation and soil heating.

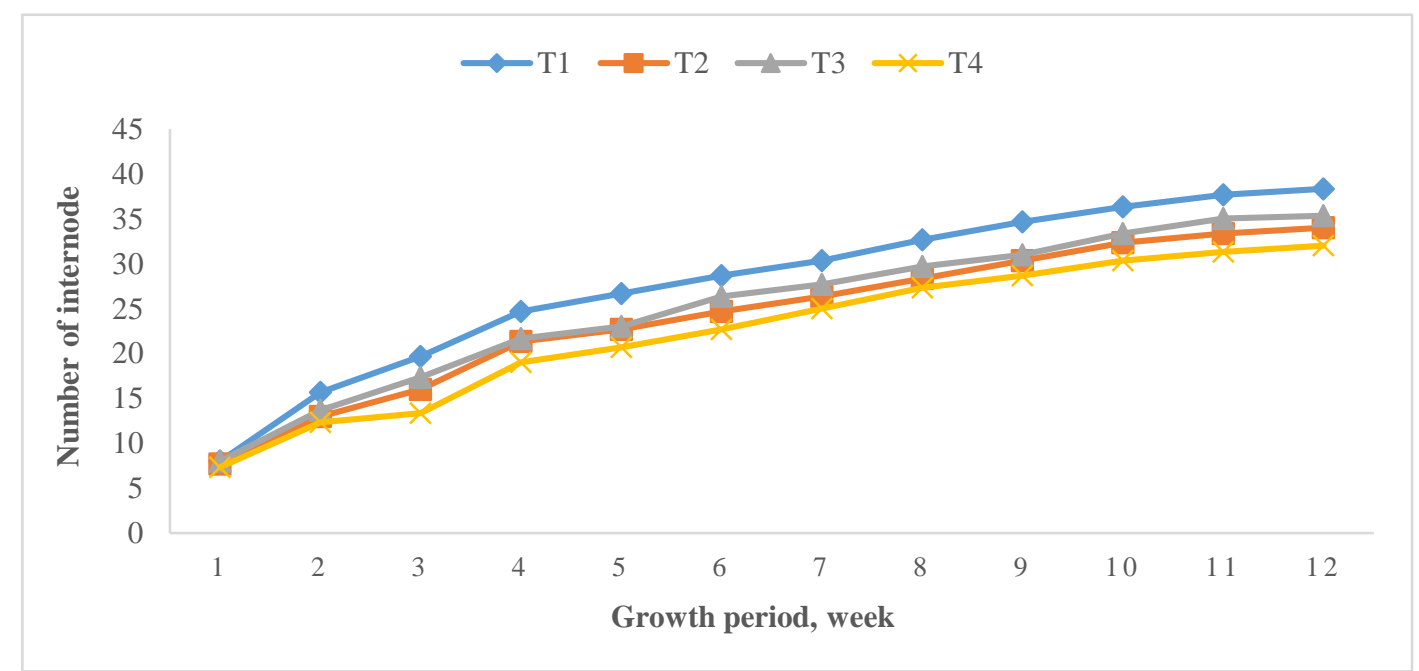

Figure (10): number of internode for cucumber plant during the growth period plant.

\section{3. 1. 5. Leaf area:}

Figure (11) shows the Leaf area of cucumber plant under different treatments (T1 to T4) during the growth period of plant. The results indicate that the Leaf area of cucumber increases linearly 
with the time and decreases linearly with the age of the plant. It could be seen that the Leaf area increased from 87.35 to $337.60,83.44$ to $302.35,85.49$ to 312.78 and 81.28 to $287.94 \mathrm{~cm}^{2}$ for $\mathrm{T} 1$ to $\mathrm{T} 4$, respectively, and decreased from 337.60 to $206.43,302.35$ to 189.43 .78 to 195.87 and 287.94 to $178.26 \mathrm{~cm}^{2}$ for T1 to T4, respectively, when the time after transplanting increased from 1 to 12 weeks.

The statistical analysis showed that difference between the average leaf area of cucumber for all treatments was significant. The results indicate that the average Leaf area was 254.21, $229.11,240.25$ and $212.90 \mathrm{~cm}^{2}$ for T1 to T4, respectively. The highest value of average Leaf area $\left(254.21 \mathrm{~cm}^{2}\right)$ was achieved with a treatment $\mathrm{T} 1$, while the lowest value of average Leaf area $\left(212.90 \mathrm{~cm}^{2}\right)$ occurred with a treatment (T4), and T1 the best and most Leaf area are due to intermittent irrigation and soil heating.

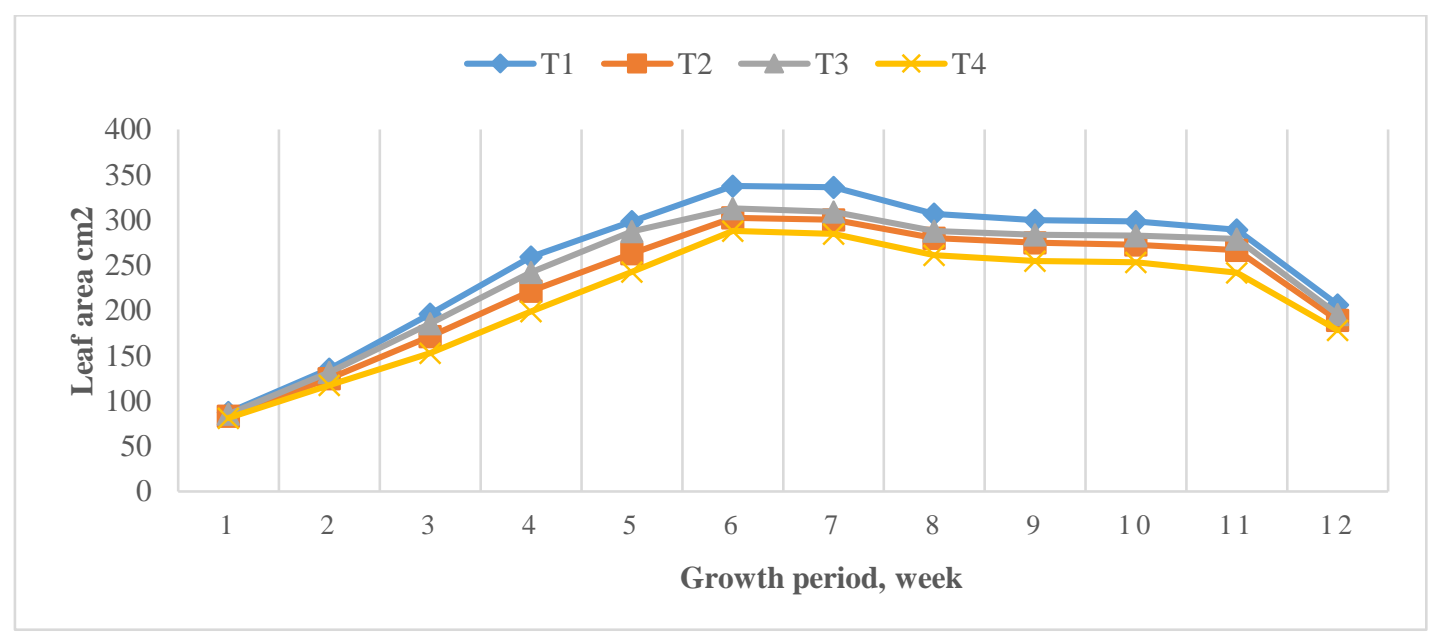

Figure (11): Leaf area of cucumber plant during the growth period plant.

\section{4. 1. Yield of cucumber plant:}

Figure (12) shows the fresh yield of cucumber for all treatments (T1 to T4) at the end of growing period. The results indicate that the total fresh yield values of cucumber crop ranged from 7474.278 to $4276.49 \mathrm{~g} \mathrm{plant}^{-1}$ for different treatments. The highest value of total fresh yield (7474.28 g plant-1) was achieved with a treatment $\mathrm{T} 1$ because this treatment recorded the intermittent irrigation and soil heating, while the lowest value of total fresh yield (4276.49 $\mathrm{g}$ plant $^{-1}$ ) was found with a treatment T4.

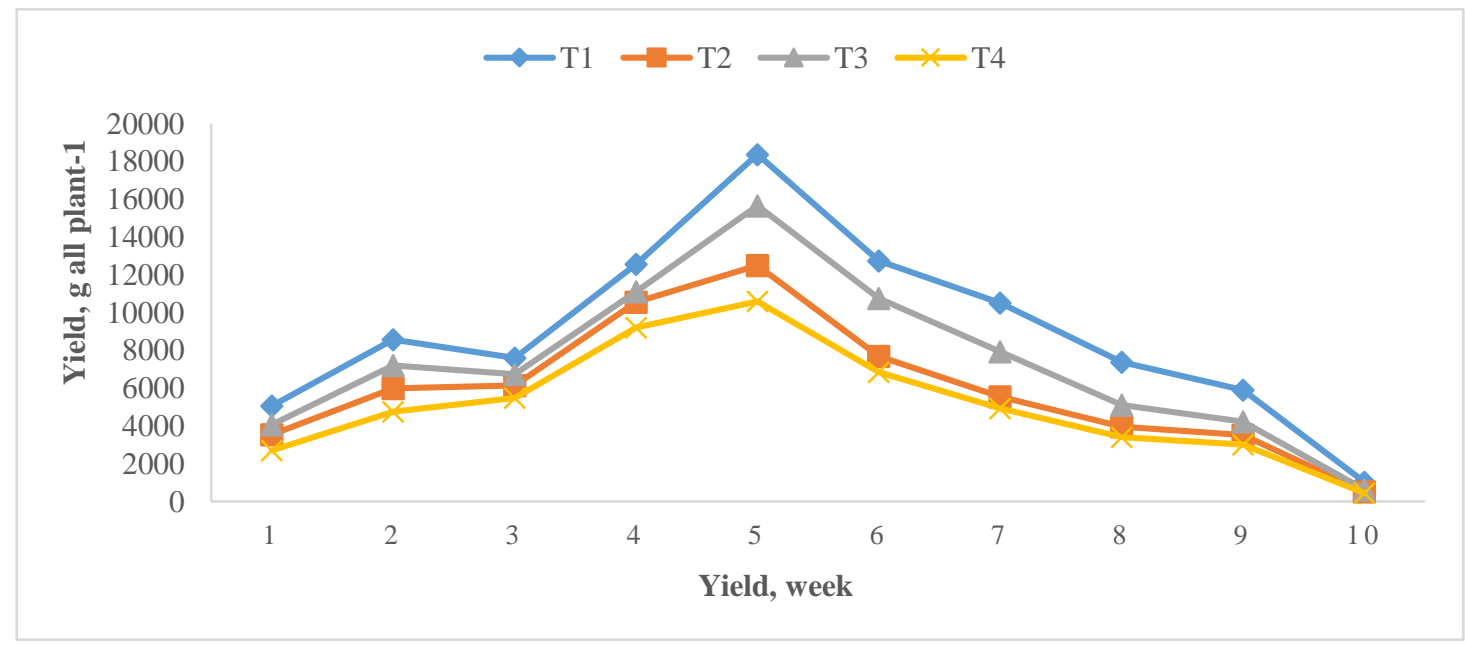

Figure (12): Average mass of fruit for cucumber plant during the growth period plant. 
These results agreed with those obtained by Shahak et al., (2008) and Milenković et al., (2012) who found that the intermittent irrigation and soil heating increased the total fresh yield which was associated with both higher productivity (number of fruits produced per plant).

The statistical analysis showed that there is a significant difference between the average fresh yield of cucumber for all treatments, the results indicate that the average fresh yield was $7474.28,4990.39,6113.94$ and $4276.49 \mathrm{~g}_{\text {plant }}{ }^{-1}$ for $\mathrm{T} 1$ to $\mathrm{T} 4$, respectively.

\section{CONCLUSION}

The experiment was carried out to study the water and nutrients reuse in closed soilless culture system and to obtain the best reused rate for nutrients after treatment and fertigation management in these systems. The obtained results can be summarized as follows:

- The average Drainage for treatments ranged from 23.94, 35.57, 27.81 and 37.70 Lit all plant ${ }^{-}$ 1 for T1, T2, T3, and T4, respectively.

- The average total nitrogen concentration in the drainage solution was the lowest in treatment T1 (8.13 ppm) compared to other all treatments; T2, T3 and T4, which the nitrogen concentrations were $14.63,10.88$, and 20.63 ppm, respectively.

- The average total phosphorus concentration in the drainage solution was the lowest in treatment T1 (10.75 ppm) compared to other all treatments; T2, T3 and T4, which the phosphorus concentrations were $15.5,12.75$, and $23.625 \mathrm{ppm}$, respectively.

- that the number of leaves increased from 7.00 to $37.33,6.67$ to $33.00,7.00$ to 34.33 and 6.33 to 31.00 for $\mathrm{T} 1$ to $\mathrm{T} 4$, respectively,

- The average potassium concentration in the drainage solution was the lowest in treatment T1 (16.875 ppm) compared to other all treatments; T2, T3 and T4, which the potassium concentrations were $23.5,19.5$, and 28.875 ppm, respectively.

- The average calcium concentration in the drainage solution was the lowest in treatment T1 (20.25 ppm) compared to other all treatments; T2, T3 and T4, which the calcium concentrations were $25.375,23.00$, and 30.25 ppm, respectively.

- The average magnesium concentration in the drainage solution was the lowest in treatment T1 (3.875 ppm) compared to other all treatments; T2, T3 and T4, which the magnesium concentrations were $7.875,5.25$, and $10.125 \mathrm{ppm}$, respectively.

- Plant height increased from 48.33 to $258.67,49.67$ to $291.00,48.33$ to 271.00 and 45.00 to 251.67 for $\mathrm{T} 1, \mathrm{~T} 2, \mathrm{~T} 3$, and $\mathrm{T} 4$, respectively.

- Number of leaves increased from 7.00 to $37.33,6.67$ to $33.00,7.00$ to 34.33 and 6.33 to 31.00 for $\mathrm{T} 1, \mathrm{~T} 2, \mathrm{~T} 3$, and $\mathrm{T} 4$, respectively.

- Stem diameter increased from 6.45 to $7.38,6.22$ to $6.98,6.35$ to 7.07 and 5.96 to $6.73 \mathrm{~mm}$ for T1 to T4, respectively, and decreased from 7.38 to $6.66,6.98$ to $6.44,7.07$ to 6.53 and 6.73 to $6.04 \mathrm{~mm}$ for $\mathrm{T} 1$ to $\mathrm{T} 4$, respectively.

- Number of internode increased from 8.00 to $38.33,7.67$ to $34.00,8.00$ to 35.33 and 7.33 to 32.00 for T1 to T4, respectively.

- Leaf area increased from 87.35 to $337.60,83.44$ to $302.35,85.49$ to 312.78 and 81.28 to $287.94 \mathrm{~cm}^{2}$ for T1 to T4, respectively, and decreased from 337.60 to $206.43,302.35$ to 189.43 .78 to 195.87 and 287.94 to $178.26 \mathrm{~cm}^{2}$ for T1 to T4, respectively.

- The total fresh yield values of cucumber crop ranged from 7474.278 to $4276.49 \mathrm{~g} \mathrm{plant}^{-1}$ for different treatments. 


\section{REFERENCES}

Dhakal. U., Salokhe V., Tantau H. and Max J. (2005). Development of a greenhouse nutrient recycling system for tomato production in humid tropics. Agricultural Engineering International: The Cigr Ejournal. Manuscript Bc 05 008. Vol. Vii.

FAO, (1991). Localized irrigation. Irrigation and Drainage, Paper No. 36:144P.

Hamdy, A., (2006). The road map towards water security, food security and environmental sustainability in arid and semi-arid mediterranean countries. In: Yazar, A., Gencel, B., Tekin, S. (Eds.), international symposium on water and land management for sustainable irrigated agriculture. , Pp. 16-44.

Ikeda, H., Koohakan P. and Jaenaksorn T. (2002). Problems and countermeasures in the re-use of the nutrient solution in soilless production. Acta Hort. 578, 213-219.

Incrocci, L., Malorgio F. Della Bartola A. and Pardossi A. (2006). The influence of drip irrigation or subirrigation on tomato grown in closed-loop substrate culture with saline water. Sci. Hort. 107, 365-372.

Kläring, H.P. (2001). Strategies to control water and nutrient supplies to greenhouse crops: A Review. Agronomie 21, 311-321.

Magen, H. (1999). Recirculating nutrient solutions in greenhouse production. 9th Ipi-Issas Regional Workshop, December 5-8, 1999, Haikoy, Hainan, Prc. Available Online At: $\underline{\text { Http://Www.Ipipotash.Org/Presentn/Rnsigp.Html. }}$

Massa, D., Mag J.J., Montesano F.F. and Tzortzakis N. (2020). Minimizing water and nutrient losses from soilless cropping in southern europe. Agricultural water management volume 241, 1 November 2020, 106395. Https://Doi.Org/10.1016/J.Agwat.2020.106395. Â@ 2020 Elsevier B.V. All Rights Reserved.

Merica, M.K., Tuzelb I.H., Tuzelc Y. and Oztekin G.B. (2011). Effects of nutrition systems and irrigation programs on tomato in soilless culture. Agricultural water management $99: 19-25$.

Milenković, L., Ilić Z.S., Đurovka M., Kapoulas N., Mirecki N. and Fallik E. (2012). Yield and pepper quality as affected by light intensity using colour shade nets. Agriculture \& Forestry, Vol. 58. Issue 1: 19-33, Podgorica.

Rouphael, Y., Colla G., Battistelli A., Moscatello S. and Rea E. (2004). Yield, water requirement, nutrient uptake and fruit quality of zucchini squash grown in soil and soilless culture. J. Hort. Sci. Biotech. 79, 423-430.

Runia, W.T. and Amsing J.J. (2001). Disinfection of recirculating water from closed cultivation systems by heat treatment. Acta Horticulture, 548: 215-222.

Shahak, Y. (2008). Photo-selective netting for improved performance of horticultural crops. A review of ornamental and vegetable studies carried out in Israel. Acta Hort. 770, ISHS: $161-168$. 


\section{اعادة استخدام المياه والمغذيات فى نظم الزراعة بدون تربة المظلقة \\ عبدالله جمال عبدالمجيد'، طه حسن عاشور 'و سمير احمد على'}

' طالب دكتور اة ـ قسم الهندسة الزر اعية ـ كلية الزر اعة بمثتهر - جامعة بنها ـ مصر.

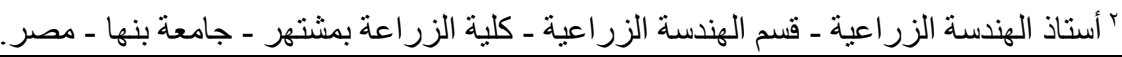

الملخص العربي الزيه

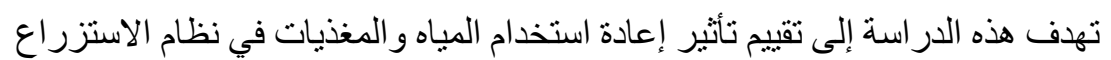

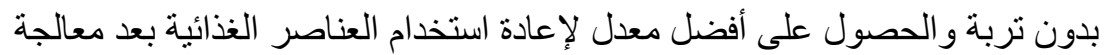

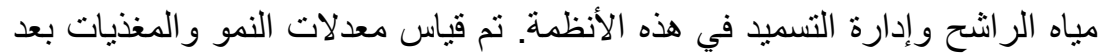
معاملات مختلفة لأوقات الري وكمية مياه الري، بالإضافة إلى تسخين منطقة الجذائور

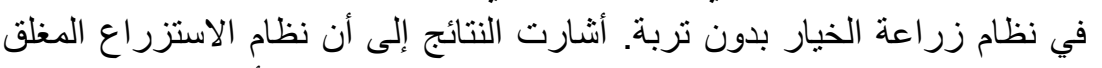

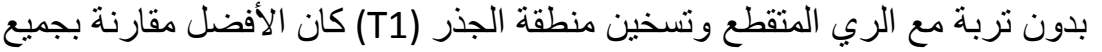

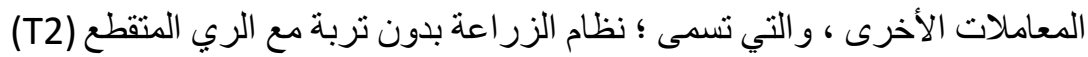

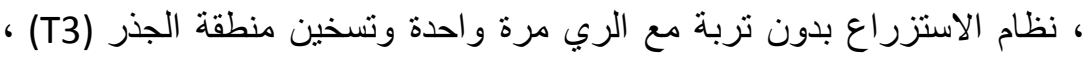

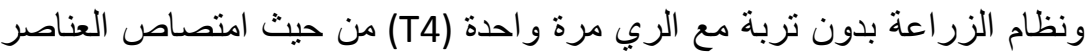

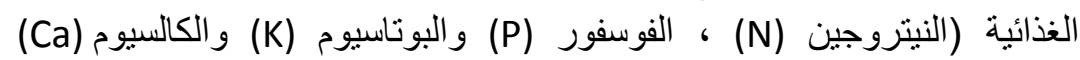

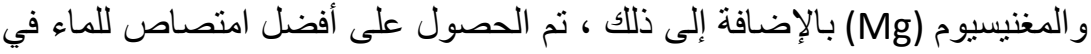

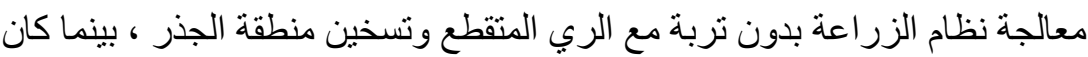

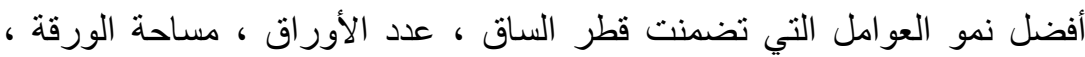

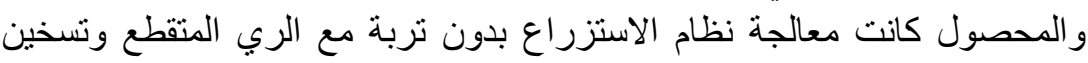

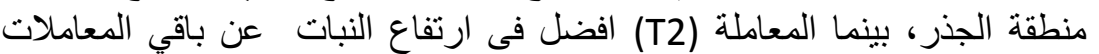
الاخرى.

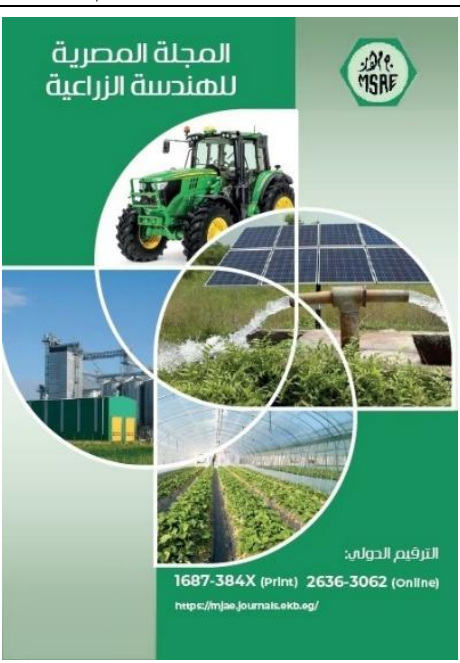

C) المجلة المصرية للهندسة الزراعية

الكلمات المفتاحية: المغذيات، الزر اعة بدون تربة، المغنة التسميد، الري، منطقة الجذور. 